\title{
STUDI PERUBAHAN TUTUPAN LAHAN DAS CILIWUNG DENGAN METODE KLASIFIKASI TERBIMBING CITRA LANDSAT 7 ETM+ MULTITEMPORAL TAHUN 2001 \& 2008 (Studi Kasus: Bogor)
}

\author{
Anindityo Budi Suryo, Teguh Hariyanto \\ Jurusan Teknik Geomatika, Fakultas Teknik Sipil dan Perencanaan, Institut Teknologi Sepuluh Nopember (ITS) \\ Jl. Arief Rahman Hakim, Surabaya 60111 Indonesia \\ e-mail: teguh_hr@geodesy.its.ac.id
}

\begin{abstract}
Abstrak
Meningkatnya pembangunan di perkotaan seringkali menimbulkan dampak tidak baik terhadap lingkungan. Salah satu contohnya adalah pembangunan yang terjadi di Daerah Aliran Sungai Ciliwung.Akibat dampak pembangunan yang tidak terencana di daerah aliran sungai menyebabkan perubahan tutupan lahan. Perubahan tutupan lahan ini berpengaruh terhadap timbulnya masalah pada daerah aliran sungai misalnya banjir, produktivitas tanah menurun, pengendapan pada waduk, saluran irigasi, proyek tenaga air, penggunaan tanah yang tidak tepat (perladangan berpindah, pertanian lahan kering dan konservasi yang tidak tepat), yang menimbulkan dampak negatif terhadap sosial ekonomi lingkungan di daerah aliran sungai.

Perubahan tutupan lahan yang terjadi dapat diidentifikasi dengan teknologi penginderaan jauh menggunakan citra satelit LANDSAT 7 ETM+. Dengan menggunakan citra satelit LANDSAT 7 ETM+tahun 2001, dan LANDSAT 7 ETM+ tahun 2008, dilakukan analisa perubahan tutupan lahan di daerah aliran sungai Ciliwung.
\end{abstract}

Kata kunci---Ciliwung, Penginderaan Jauh, Landsat

\section{PENDAHULUAN}

\section{Latar Belakang}

Tutupan lahan adalah segala yang meliputi jenis kenampakan yang ada di permukaan bumi pada lahan tertentu. Berbeda dengan penggunaan lahan yang meliputi segala jenis kenampakan dan sudah dikaitkan dengan kegiatan manusia dalam memanfaatkan lahan.Tutupan lahan merupakan istilah yang digunakan untuk meyebutkan suatu kenampakan lahan secara fisik, baik kenampakan alami maupun kenampakan buatan manusia, misalnya sawah, hutan, pemukiman, perkebunan, badan air, dan lahan kosong.

Hulu daerah aliran sungai Ciliwung meliputi sebagian wilayah kabupaten Bogor. Daerah aliran sungaiCiliwung secara geografis terletak pada 106ㄴㅇ'40"-10700'15" bujur timur dan 638'15" 6046'05" lintang selatan. Perlu adanya pemantauan terhadap perubahan tutupan lahan yang terjadi untuk menanggulani dampak yang ditimbulkan serta untuk acuan dalam menentukan kebijakan lebih lanjut seperti dalam pengembangan wilayah.

Tutupan lahan merupakan sesuatu yang tidak tetap, atau dikatakan sesuatu yangdapat berubah.Menganalisa tutupan lahan menggunakan metode konvensional ternyata tidak mencukupi lagi, dengan berkembangnya teknologi penginderaan jauh menjadikan ini salah satu teknik yang digunakan untuk menganalisa tutupan lahan. Dan untuk mengetahui kondisi tutupan lahan yang terjadi pada tahun 2001 dan 2008 dengan menggunakan citra satelitLANDSAT ETM 7 multitemporal tahun 2001 dan 2008, dengan perbedaan tujuh tahun dapat diketahui perubahan yang cukup signifikan untuk perubahan tutupan lahan. Dilakukan analisa perubahan tutupan lahan di daerah aliran sungai Ciliwung dengan menggunakan metode klasifikasi terbimbing.

Penelitian ini dapat memberikan informasi terkini mengenai kondisi tutupan lahan di sekitar hulu daerah aliran sungai Ciliwung.

\section{METODOLOGI PENELITIAN \\ Lokasi Penelitian \\ Penelitian ini dilakukan di DAS Ciliwung Hulu seluas 14.860 ha secara geografis terletak pada 10649'40" - 107000'15" Bujur Timur (BT) dan 6038'15“ LS - 646'05” Lintang Selatan (LS).}




\section{Data dan Perangkat Lunak}

\section{- Data}

Data yang digunakan dalam penelitian ini adalah:

1. Data citra satelit LANDSAT+7 tahun 2001 dan 2008, wilayah daerah aliran sunagi Ciliwung.

2. Peta Topografi (RBI) skala 1:25.000

3. Landsat Ortho Path/Row 122065

\section{- Peralatan}

Perangkat lunak untuk analisis indeks vegetasi adalah:

1. Program pengolahan Citra Er Mapper 7.0

2. ArcView 3.3

3. Autodesk Land Desktop 2004

4. EasyGPS

\section{Deskripsi Citra LANDSAT 7ETM+}

Satelit LANDSAT 7 ETM+yang diluncurkan pada 15 April 1999 adalah satelit penginderaan. Landsat 7 mempunyai resolusi spectral 8 band, resolusi radiometrik 8 bit, resolusi temporal 16 hari, dan resolusi spasial $30 \mathrm{~m} \times 30 \mathrm{~m}$ (band visible, near infrared, dan midlle infrared), $60 \mathrm{~m}$ x $60 \mathrm{~m}$ (band thermal) dan $15 \mathrm{~m} \times 15 \mathrm{~m}$ (band pankromatik) (Purwadhi, 2001)

\section{HASIL DAN PEMBAHASAN}

Koreksi Geometrik Citradilakukan dengan memberikan titik kontrol permukaan atau biasa disebut dengan ground control point (GCP) dari citra referensi Landsat-7 ETM ortho pada citra yang belum terkoreksi dan diproses dengan menggunkan menu Geocoding Wizard pada perangkat lunak ER Mapper 7.0.

Sistem proyeksi yang digunakan adalah Universal Transverse Mercator zone 48s dan datum yang dipakai adalah WGS 1984. Hasil koreksi geometrik pada citra Landsat 7 ETM+ tahun 2001 yaitu sebesar 0.86 piksel untuk nilai total $R M S_{\text {error }}$ dan sebesar 0.095 piksel untuk nilai rata-rata $R M S_{\text {error }}$.

Sedangkan hasil koreksi geometrik pada citra Landsat 7 ETM+ tahun 2008 yaitu sebesar 0.74 piksel untuk nilai total $R M S_{\text {error }}$ dan sebesar 0.082 piksel untuk nilai rata-rata $R M S_{\text {error }}$.
Tabel 1.Nilai RMSerror pada Citra Landsat-7 ETM+

\begin{tabular}{lllll}
\hline No. & Tahun & $\begin{array}{l}\text { Jumlah } \\
\text { GCP }\end{array}$ & $\begin{array}{l}\text { Total } \\
\text { RMSerror }\end{array}$ & $\begin{array}{l}\text { Rata-Rata } \\
\text { RMSerror }\end{array}$ \\
\hline 1. & 2001 & 9 & 0.86 & 0.095 \\
2. & 2008 & 9 & 0.74 & 0.082 \\
\hline
\end{tabular}

Menurut Purwadhi (2001) dalam Anthoni (2011) dalam Fitrianingtyas (2012), batas kesalahan pada proses koreksi geometrik untuk mendeteksi perubahan tutupan lahan yaitu 0.5 atau 1 piksel satu sama lain atau sekitar 15-30 meter (1piksel= 30x30meter)C untuk citra Landsat-7 ETM. Sehingga jika pergeseran titik lebih dari batas toleransi maka koreksi harus diulang.

\section{Klasifikasi Citra}

Meliputi sekumpulan algoritma yang didasari pemasukan contoh objek oleh operator. Contoh ini disebut sampel, dan lokasi geografis kelompok piksel sampel ini disebut sebagai daerah contoh.

Klasifikasi dilakukan dengan training sampe sebanyak 81 area. Jumlah kelas yang digunakan tujuh kelas tutupan lahan yaitu seperti dijelaskan dalam table dibawah ini:

Tabel 2. Kelas Tutupan Lahan

\begin{tabular}{ll}
\hline No & Kelas \\
\hline 1 & Hutan \\
2 & Awan \\
3 & Pemukiman \\
4 & Sawah \\
5 & Perkebunan \\
6 & Badan Air \\
7 & Lahan Kosong \\
\hline
\end{tabular}

\section{MaximumLikellihood}

Gambar 1. Tabel Tutupan Lahan Citra Landsat Tahun 2001

\begin{tabular}{|c|l|r|r|}
\hline No & \multicolumn{1}{|c|}{ Kelas, } & Luas, Area (Ha) & \multicolumn{1}{c|}{$\%$} \\
\hline 1 & Hutan & $10,080.733$ & 26.831 \\
2 & Awan & $4,648.507$ & 12.373 \\
3 & Pemukiman & $1,989.660$ & 5.296 \\
4 & Sawah & $7,466.600$ & 19.873 \\
5 & Perkebunan & $5,612.613$ & 14.939 \\
6 & Badan Air & 515.431 & 1.372 \\
7 & LahanKosong & $7,257.512$ & 19.317 \\
\hline \multicolumn{2}{|c|}{ Total } & $37,571.055$ & 100 \\
\hline
\end{tabular}




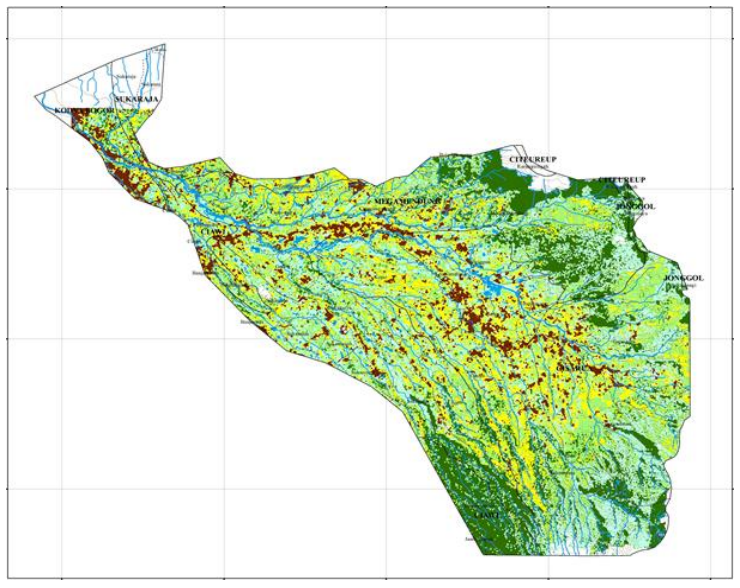

Gambar 2. Citra hasil klasifikasi tutupan lahan menggunakan citra Landsat tahun 2001

\begin{tabular}{|c|l|r|r|}
\hline No & \multicolumn{1}{|c|}{ Kelas, } & \multicolumn{1}{c|}{ Luas, Area $(\mathrm{Ha})$} & \multicolumn{1}{c|}{$\%$} \\
\hline 1 & Hutan & $12,539.318$ & 33.799 \\
2 & Awam & $7,350.728$ & 19.814 \\
3 & Pemukiman & $2,315.501$ & 6.241 \\
4 & Sawah & $4,254.082$ & 11.467 \\
5 & Perkebunan & $8,666.843$ & 23.361 \\
6 & Badan Air & 688.793 & 1.854 \\
7 & LahanKosong & $1,284.938$ & 3.464 \\
\hline \multicolumn{2}{|c|}{ Total } & $37,100.202$ & 100 \\
\hline
\end{tabular}

Gambar 3. Tabel Tutupan Lahan Citra Landsat Tahun 2008

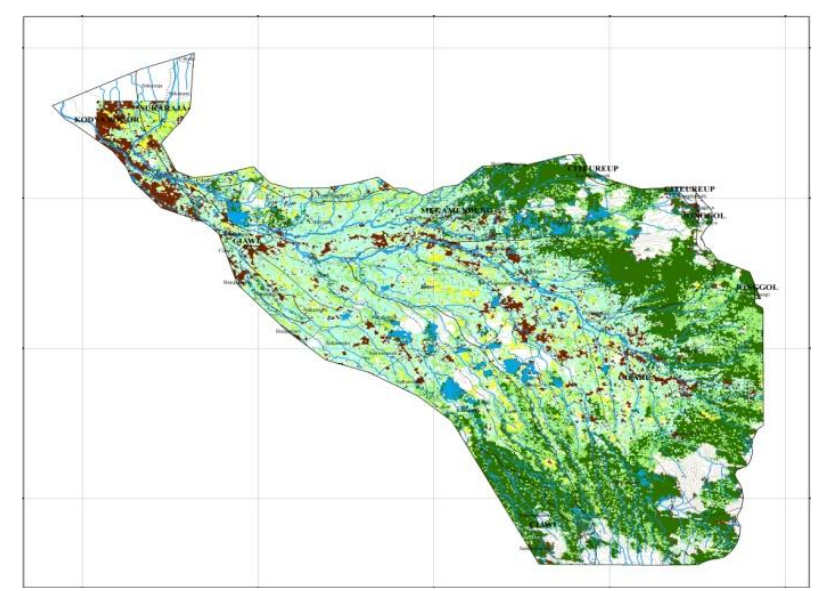

Gambar 4. Citra hasil klasifikasi tutupan lahan menggunakan citra Landsat tahun 2008

\section{Parallelepiped}

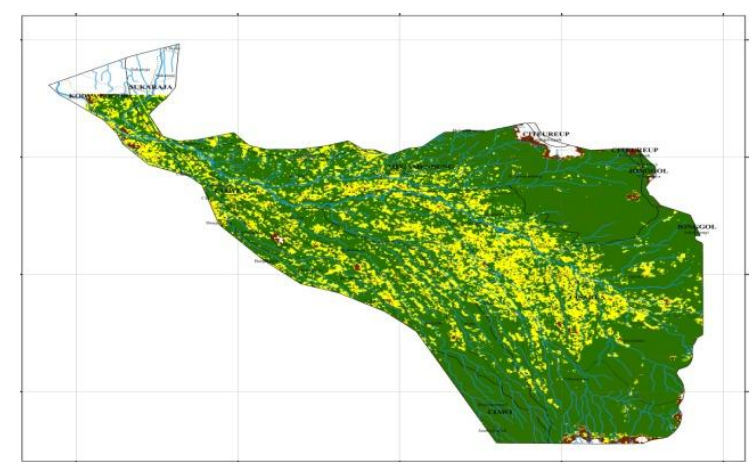

Gambar 5. Citra hasil klasifikasi tutupan lahan menggunaka metode parallelepiped pada citra Landsat tahun 2001

\begin{tabular}{|c|l|r|r|}
\hline No & \multicolumn{1}{|c|}{ Kelas, } & \multicolumn{1}{c|}{ Luas, Area $(\mathrm{Ha})$} & $\%$ \\
\hline 1 & Hutan & $25,601.968$ & 68.143 \\
2 & Awan & $7,174.111$ & 19.095 \\
3 & Pemukiman & $1,769.236$ & 4.709 \\
4 & Sawah & $3,025.740$ & 8.053 \\
5 & Perkebunan & 0.000 & 0.000 \\
6 & Badan Air & 0.000 & 0.000 \\
7 & LahanKosong & 0.000 & 0.000 \\
\hline \multicolumn{2}{|c|}{ Total } & $37,571.055$ & 100 \\
\hline
\end{tabular}

Gambar 6. Tabel Tutupan Lahan Hasil Metode Parallelepiped Citra Landsat Tahun 2001

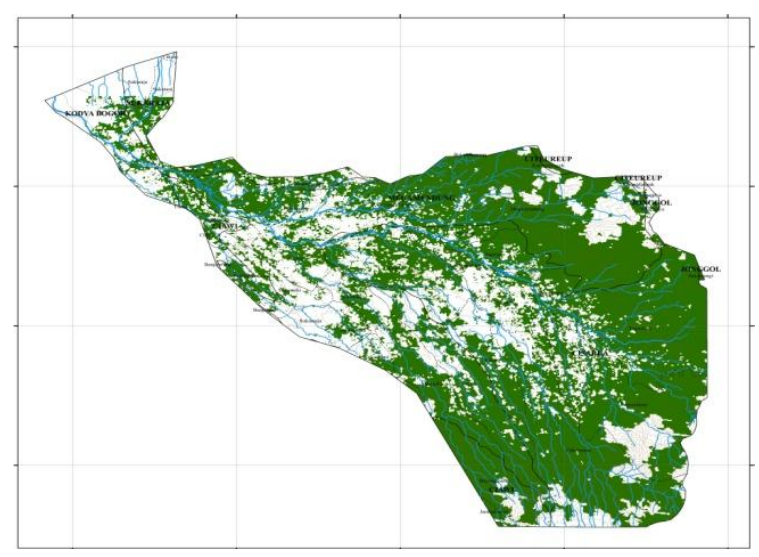

Gambar 7. Citra hasil klasifikasi tutupan lahan menggunakan metode parallelepiped pada citra Landsat tahun 2008 


\begin{tabular}{|c|l|r|r|}
\hline No & \multicolumn{1}{|c|}{ Kelas, } & \multicolumn{1}{c|}{ Luas, Area $(\mathrm{Ha})$} & \multicolumn{1}{l|}{$\%$} \\
\hline 1 & Hutan & $24,978.075$ & 67.328 \\
2 & Awan & $12,121.127$ & 32.672 \\
3 & Pemukiman & 0.000 & 0.000 \\
4 & Sawah & 0.000 & 0.000 \\
5 & Perkebunan & 0.000 & 0.000 \\
6 & Badan Air & 0.000 & 0.000 \\
7 & LahanKosong & 0.000 & 0.000 \\
\hline \multicolumn{2}{|c|}{ Total } & $37,099.203$ & 100 \\
\hline
\end{tabular}

Gambar 8. Tabel Tutupan Lahan Hasil Metode Parallelepiped Citra Landsat Tahun 2008

\section{Minimum Distance}

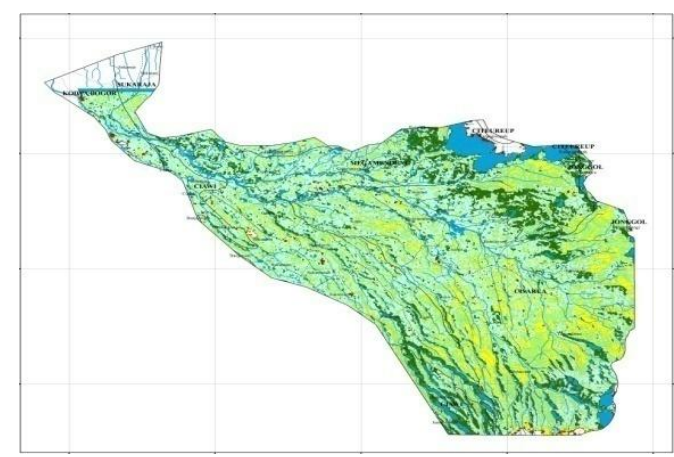

Gambar 9. Citra hasil klasifikasi tutupan lahan menggunaka metode minimum distance pada citra Landsat tahun 2001

\begin{tabular}{|c|l|r|r|}
\hline No & \multicolumn{1}{|c|}{ Kelas, } & \multicolumn{1}{c|}{ Luas, Area $(\mathrm{Ha})$} & \multicolumn{1}{c|}{$\%$} \\
\hline 1 & Hutan & $6,400.289$ & 17.035 \\
2 & Awan & $3,662.269$ & 9.748 \\
3 & Pemukiman & 967.524 & 2.575 \\
4 & Sawah & $2,528.753$ & 6.731 \\
5 & Perkebunan & $8,207.492$ & 21.845 \\
6 & Badan Air & $12,848.892$ & 34.199 \\
7 & LahanKosong & $2,955.835$ & 7.867 \\
\hline \multicolumn{2}{|c|}{ Total } & $37,571.055$ & 100 \\
\hline
\end{tabular}

Gambar 10. Tabel Tutupan Lahan Hasil Metode Minimum Distance Citra Landsat Tahun 2001

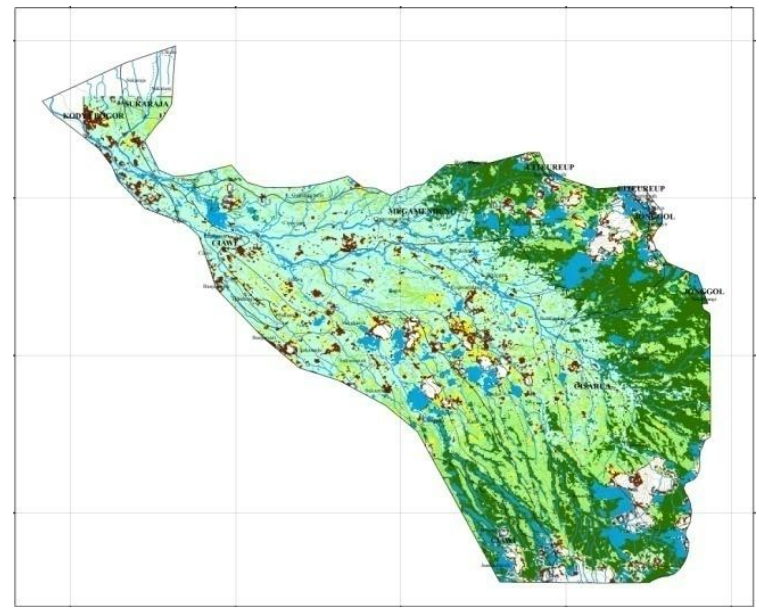

Gambar 11. Citra hasil klasifikasi tutupan lahan menggunaka metode minimum distance pada citra Landsat tahun 2008

\begin{tabular}{|c|l|r|r|}
\hline No & \multicolumn{1}{|c|}{ Kelas, } & \multicolumn{1}{c|}{ Luas, Area (Ha) } & \multicolumn{1}{c|}{$\%$} \\
\hline 1 & Hutan & $7,648.895$ & 20.617 \\
2 & Awan & $2,737.837$ & 7.380 \\
3 & Pemukiman & $2,281.621$ & 6.150 \\
4 & Sawah & $5,990.280$ & 16.147 \\
5 & Perkebunan & $13,632.867$ & 36.747 \\
6 & Badan Air & $3,212.795$ & 8.660 \\
7 & LahanKosong & $1,594.909$ & 4.299 \\
\hline \multicolumn{2}{|c|}{ Total } & $37,099.202$ & 100 \\
\hline
\end{tabular}

Gambar 12. Tabel Tutupan Lahan Hasil Metode Minimum Distance Citra Landsat Tahun 2008

\section{Mahalanobis Distance}

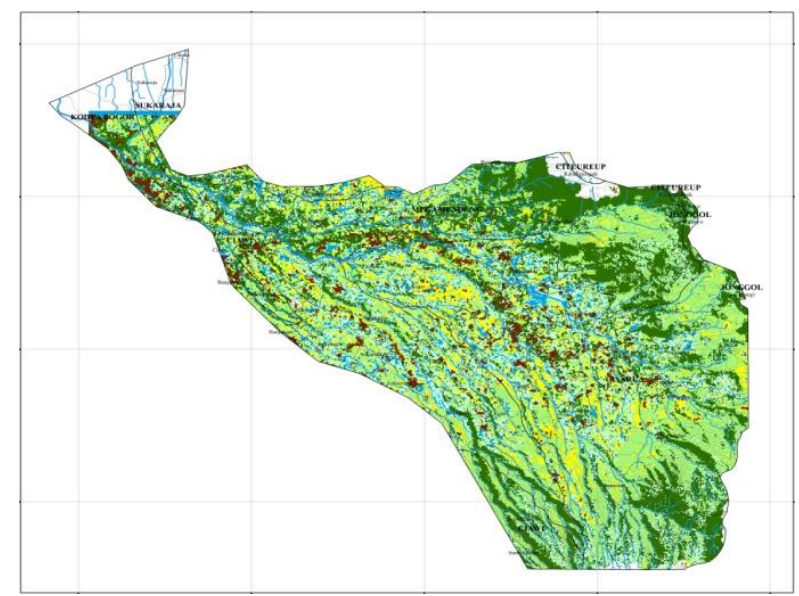

Gambar 13. Citra hasil klasifikasi tutupan lahan menggunaka metode mahalanobis distancepada citra Landsat tahun 2001 


\begin{tabular}{|c|l|r|r|}
\hline No & \multicolumn{1}{|c|}{ Kelas, } & \multicolumn{1}{c|}{ Luas, Area $(\mathrm{Ha})$} & \multicolumn{1}{c|}{$\%$} \\
\hline 1 & Hutan & $11,103.768$ & 29.554 \\
2 & Awam & $4,426.644$ & 11.782 \\
3 & Pemukiman & $1,590.288$ & 4.233 \\
4 & Sawah & $2,807.116$ & 7.471 \\
5 & Perkebunan & $8,603.085$ & 22.898 \\
6 & Badan Air & $7,177.800$ & 19.105 \\
7 & LahanKosong & $1,862.354$ & 4.957 \\
\hline \multicolumn{2}{|c|}{ Total } & $37,571.055$ & 100 \\
\hline
\end{tabular}

Gambar 13. Tabel Tutupan Lahan Hasil Metode Mahalanobis Distance Citra Landsat Tahun 2001

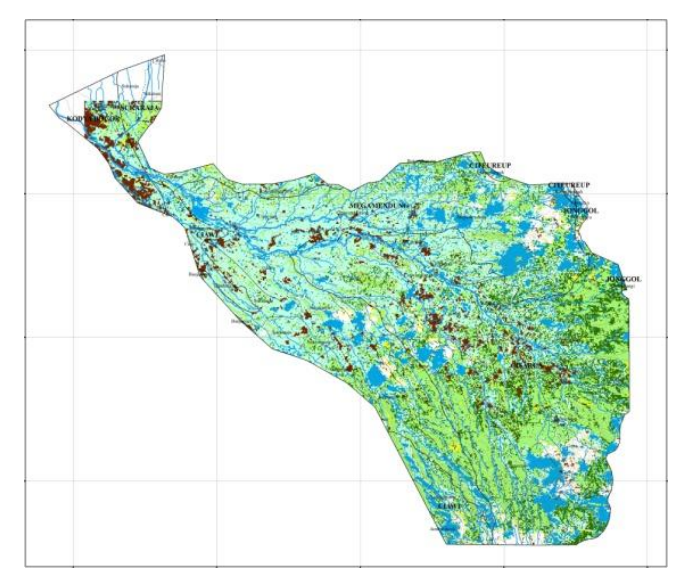

Gambar 14. Citra hasil klasifikasi tutupan lahan menggunakan metode mahalanobis distancepada citra Landsat tahun 2008

\begin{tabular}{|c|l|r|r}
\hline No & \multicolumn{1}{|c|}{ Kelas } & Luduas Area (Ha) & \multicolumn{1}{c}{$\%$} \\
\hline 1 & Hutan & $3,623.056$ & 9.7 \\
2 & Awan & $2,664.849$ & 7.1 \\
3 & Pemulkiman & $1,731.242$ & 4.6 \\
4 & Sawah & $7,184.389$ & 19.3 \\
5 & Perkebunan & $15,849.880$ & 42.7 \\
6 & Badam Air & $4,636.679$ & 12.4 \\
7 & LahanKosong & $1,409.107$ & 3.7 \\
\hline \multicolumn{2}{|c|}{ Total } & $37,099.202$ & 1 \\
\hline
\end{tabular}

Gambar 15. Tabel Tutupan Lahan Hasil Metode Mahalanobis Distance Citra Landsat Tahun 2008

\section{Analisa}

\section{Tutupan Lahan}

Luas tutupan lahan wilayah penelitian diproleh dari hasil klasifikasi citra Landsat 7 ETM+ tahun 2001 dan 2008. Luasan tersebut didapat dari software ENVI4.6.1. Luas tutupan lahan adalah :

\begin{tabular}{|c|c|c|c|c|c|}
\hline No & Kelas & $\begin{array}{c}\text { Maximum } \\
\text { Likelihood }\end{array}$ & Parallelepiped & $\begin{array}{c}\text { Minimum } \\
\text { Distance }\end{array}$ & $\begin{array}{c}\text { Mahalanobis } \\
\text { Distance }\end{array}$ \\
\hline 1 & Hutan & $10,080.73$ & 25601.97 & $6,400.29$ & $11,103.77$ \\
2 & Awan & $4,648.51$ & 7174.11 & $3,662.27$ & $4,426.64$ \\
3 & Pemukiman & $1,989.66$ & 1769.24 & 967.52 & $1,590.29$ \\
4 & Sawah & $7,466.60$ & 3025.74 & $2,528.75$ & $2,807.12$ \\
5 & Perkebunan & $5,612.61$ & 0 & $8,207.49$ & $8,603.09$ \\
6 & Badan Air & 515.43 & 0 & $12,848.89$ & $7,177.80$ \\
7 & Lahan Kosong & $7,257.51$ & 0 & $2,955.83$ & $1,862.35$ \\
\hline & Total & $37,571.05$ & 37571.05 & $37,571.05$ & $37,571.05$ \\
\hline
\end{tabular}

Gambar 16. Luasan Tutupan Lahan Landsat Tahun 2001

\begin{tabular}{|c|c|c|c|c|c|}
\hline No & Kelas & $\begin{array}{c}\text { Maximos } \\
\text { Likslihood }\end{array}$ & Parallslepiped & $\begin{array}{l}\text { Minimum } \\
\text { Distance }\end{array}$ & $\begin{array}{l}\text { Mahalanghis } \\
\text { Distance }\end{array}$ \\
\hline 1 & Hutan & $12,539.32$ & $24,978.08$ & $7,648.89$ & $3,623.06$ \\
\hline 2 & Awsan & $7,350.73$ & $12,121.13$ & $2,737.84$ & $2,664.85$ \\
\hline 3 & Pemuleiman & $2,315.50$ & 0 & $2,281.62$ & $1,731.24$ \\
\hline 4 & Sayxah & $4,254.08$ & 0 & $5,990.28$ & $7,184.39$ \\
\hline 5 & Perkebunan & $8,666.84$ & 0 & $13,632.87$ & $15,849.88$ \\
\hline 6 & Badan Air & 688.79 & 0 & $3,212.80$ & $4,636.68$ \\
\hline \multirow[t]{2}{*}{7} & LahanKosong & $1,284.94$ & 0 & $1,594.91$ & $1,409.11$ \\
\hline & Total & $37,100.20$ & $37,099.20$ & $37,099.20$ & $37,099.20$ \\
\hline
\end{tabular}

\section{Gambar 17. Tabel Luasan Tutupan Lahan Landsat} Tahun 2008

\section{KESIMPULAN DAN SARAN}

Kesimpulan yang diperoleh berdasarkan hasil penelitian ini antara lain :

1. Metode klasifikasi terbimbing dengan menggunakan citra multitemporal merupakan cara yang baik digunakan untuk mengetahui perubahan tutupan lahan.

2. Dari hasil seleksi data citra Landsat ETM+ daerah penelitian, disimpulkan bahwa hasil fusi terbaik adalah multispekral komposit 542 kenampakan penutup lahan.

3. Hasil dari penelitian ini adalah perubahan tutupan

lahan tahun 2001 \& 2008 dengan menggunakan empat metode klasifikasi terbimbing. Metode Maximum likelihood dengan luas area hutan bertambah $24,39 \%$, luas area pemukiman bertambah $16,38 \%$, luas area sawah berkurang $43,03 \%$, luas area perkebunan bertambah $54,42 \%$, luas area badan air bertambah $33,63 \%$, dan luas area lahan kosong berkurang $82,30 \%$.

4. Dari beberapa metode yang digunakan dalam penentuan area tutupan lahan, secara berurutan dari yang sesuai hingga titak sesuai adalah Maximum likelihood, Minimum distance, Mahalanobis distance, dan Paralleelepiped. 


\section{Saran}

Adapun saran dari penelitian ini antara lain :

1. Teknologi penginderaan jauh disarankan sebagai salah satu alternatif dalam mendukung pengembangan sistem pemantauan perubahan tutupan lahan saat ini.

2. Untuk mengembangkan penelitian ini, diharapkan menggunakan citra satelit dengan ketelitian yang lebih tinggi.

3. Selain memahami proses teknik analisa dalam software kita juga perlu memahami sifat khas suatu objek untuk mempermudah pada saat melakukan interpretasi.

4. Dalam menganalisa data citra satelit multitemporal dengan tahun yang berbeda sebaiknya digunakan yang memiliki tanggal yang sama dimana mempengaruhi tingkat keakuratan data tersebut.

5. Rekomendasi untuk perbaikan lahan meliputi restorasi dan reklamasi. Restorasi merupakan upaya perbaikan lahan agar lahan tersebut bisa difungsikan lagi ke penggunaan awalnya, sedangkan reklamasi adalah upaya perbaikan suatu lahan yang rusak dan digunakan untuk penggunaan lain.

\section{DAFTAR PUSTAKA}

Anderson, J.R., Ernest E.H., John T.R., dan Richard W. 1976. A Land Use and Land Cover Classification System For Use With Remote Sensor Data. Washington: United States Printing Office.

Atmapradhana, T. 2010. Evaluasi Rencana Detil Tata Ruang Kota (RDTRK) Surabaya Unit Pengembangan (UP) Satelit Menggunakan Citra Satelit Quickbird. Surabaya : Teknik Geomatika FTSP-ITS.

Campbell, J.B. 1987. Introduction to Remote Sensimg. New York : The Guilford Express.

Danoedoro, P. 1996. Pengolahan Citra Digital : Teori dan Aplikasi dalam Bidang Penginderaan Jauh. Yogyakarta : Fakultas Geografi Universitas Gadjah Mada.

Ginanjar, W.R. 2010.Klasifikasi Perubahan Peruntukan Lahan dalam Rencana Detil Tata

Ruang Kota (RDTRK) Surabaya Unit Pengembangan (UP) VIII Satelit Menggunakan Citra Satelit Quickbird.Surabaya : Teknik Geomatika FTSP-ITS.
Jensen, J.R. 1986. Introductory to Digital Image Processing. A. Remote Sensing Perspective. Second Edition. New Jersey : Prentice Hall.

Lillesand, T.M., dan R.W. Kiefer. 1994. Penginderaan Jauh dan Interpretasi Citra. Alih Bahasa: Dulbahri. Yogyakarta : Gajah Mada University Press. 